\title{
The Impact of Integrated Maintenance Actions Optimization on Strategic Machines Lifetime
}

\author{
Mohammed Abdellatif BENSACI ${ }^{1}$, Aoul Elias HADJADJ ${ }^{2}$ \\ ${ }^{1}$ Department of Hydrocarbon production, Faculty of Hydrocarbons and Energies Renewables \\ and pieces of land, University of Ouargla, Algeria, e-mail: bensaci.ab@ouargla-univ.dz\& \\ abdelatif.bensaci@gmail.com \\ ${ }^{2}$ Department of Electromechanics, Faculty of Engineering Sciences University of Annaba, \\ Algeria e-mail: hadjadj.elias@yahoo.fr
}

Manuscript received January 20, 2020; revised October 23, 2020

\begin{abstract}
This article is based on the quantitative study of reliability, maintainability, availability $(R M A)$, on the Pareto diagram $(A B C)$ and on the analysis of the failure modes and their impact on criticality (FMECA). The developed approach aims, at first, implementing two optimization procedures (code development, Simulink modelling in MATLAB) and using two methods (graphical, analytic) of the Weibull parameters. The results obtained via code (which is based on the Weibull graph method of two parameters) are a bit divergent. The evaluation criteria are rather far from that of the model (which is based on the maximum likelihood of three-parameter Weibull distribution). This will allow to locate the critical elements, and to determine the systematic preventive time of replacements. An application case validates the proposed study objective.
\end{abstract}

Keywords: Optimization, Maintenance, Weibull, MATLAB, Impact, Maximum likelihood

\section{Introduction}

In a context of maintaining the strategic machines of the hydrocarbon sector, particularly that of the processing units at high levels of readiness, the optimization of maintenance actions $R M A, A B C, F M E C A$ is one of the key elements to consider to have an impact on the readiness during the lifetime of these machines and especially that of the critical element. An integrated maintenance approach integrates several steps aimed at this objective, using a Simulink model and a calculation code in MATLAB.

In the first step, a historical file analysis on the selected machine in a fixed period of time is made, which will enable carrying out the quantitative study of $R M A, A B C$ in order to optimize the parameters of performance and to have their 
impact on lifetime. For this study, several laws of distribution can be applied, in particular the Weibull one, whose main properties are expressed by the table below:

Table 1: Main properties of the Weibull-distribution [1]

\begin{tabular}{|c|c|c|c|}
\hline Reliability & Density of probability & Function of division & Failure rate \\
\hline$R(t)=\mathrm{e}^{-\left[\frac{t-\gamma}{\eta}\right]^{a}}$ & $f(t)=\frac{\beta}{\eta} \cdot\left[\frac{t-\gamma}{\eta}\right]^{\beta-1} \cdot \mathrm{e}^{\left.-\frac{t-\gamma}{\eta}\right]^{\beta}}$ & $F(t)=1-\mathrm{e}^{-\left[\frac{t-\gamma}{\eta}\right]^{\beta}}$ & $\lambda(t)=\frac{f(t)}{R(t)}=\frac{\beta}{\eta}\left[\frac{t-\gamma}{\eta}\right]$ \\
\hline
\end{tabular}

$\beta$ : Shape parameter (without unit);

$\eta$ : Scale parameter (unit of time);

$\gamma$ : Position parameter (unit of time).

These optimized parameters are based on the form parameter $\beta$ and the average operating time before the first failure, or meantime before failure $M T B F$ for repairable systems [2]. Knowing these indicators makes it possible to update the evolution of the failure rate during the lifetime of a machine. Updating the evolution period of this rate makes it possible to characterize the category of the failure type as well and to locate the faulty element(s) to optimize the criticality in FMECA, then to define an adequate maintenance policy. This article highlights the optimization impact of $R M A, A B C, F M E C A$ on the life of a boosting station " $K-101-A$ " motor-compressor assembly at the Haoud-Berkaoui $(H B K)$ production center of Sonatrach, based on Weibull-distribution law of two and three parameters and based on the history of failures and feedback.

\section{Approach and methodology}

The following methodology was adopted.

\section{A. Quantitative study}

Based on feedback, as currently practiced in institutions, through the implementation of a system of reporting adverse events, optimization could be made by the use of Pareto-diagram $(A B C)$ method. The various operating times were recorded according to the machine's history file, exploiting the fault history during a limited period. They were classified in an ascending order. The distribution function of the probability associated with these data is calculated using empirical relations according to the size of data. 
Table 2: Empirical relations by size of data [3]

\begin{tabular}{|c|c|c|}
\hline Sample size & Formula & Cumulative frequency \\
\hline$N \leq 30$ & Median rank & $F_{i}=\frac{i-0.3}{N+0.4}$ \\
\hline
\end{tabular}

The two procedures (code calculation, Simulink modelling) are used to find the matching values of the parameters $\beta, \eta$ and $\gamma$ of Weibull-distribution, which optimize the best available data. There are several estimation methods to perform this case study, accordingly to the two applied procedures. The graphical method (Weibull paper) is the basis of the calculation code and the analytical method (maximum likelihood) is the basis of the Simulink modelling.

To determine whether Weibull-distribution application is acceptable or not, the Kolmogorov-Smirnov test is performed. The KS test is used to determine if a sample has come from an assumed continuous probability distribution which consists of calculating the difference between the estimated $F(t i)$ empirical distribution function and the $F(t)$ theoretical one and takes the maximum of the differences in absolute value $\left(D_{n \cdot \max }\right)$. This value is compared with the $D_{n . \alpha}$ limiting value corresponding to the level $\alpha$ of confidence which is obtained from the table of Kolmogorov-Smirnov test. If $D_{n . \max }>D_{n . \alpha}$, the application is declined [3].

The graphical method: On the functional Allan Weibull paper, we represent the set of nodes $M_{i}\left(t_{i}, F\left(t_{i}\right)\right)$, where $t_{i}$ represents the time (here it is the time between failures, $T B F)$ and $F\left(t_{i}\right)$ is the frequency estimated by the middle ranks. The Weibull functional paper makes possible to find the two parameters $\beta$ and $\eta$ [4]. The distribution function associated with a Weibull-law with the parameters $\beta$ and $\eta(\gamma=0)$ is defined by:

$$
F(t)=1-e^{-\left(\frac{t}{\eta}\right)^{\beta}} .
$$

Fitting of the parameters of the Weibull distribution to data can be visually done using the Weibull plot (Fig. 1): on this plot the observed data must be laid along a straight line. This Weibull line is determined by the used calculation code.

The maximum likelihood method: In this method, a system of maximum likelihood function equations with three parameters of Weibull-distribution is established in the first step. Then an adaptive Simulink model is used to solve the equations, which cannot overcome in all cases the limitations of the traditional numerical methods as its efficiency is low [5]. The three-parameter Weibull distribution model is expressed by the following probability density function: 


$$
f(t)=\frac{m}{\eta}\left(\frac{t-\gamma}{\eta}\right)^{m-1} \cdot \exp \left(-\left(\frac{t-\gamma}{\eta}\right)^{m}\right),
$$

where: $m$ is the shape parameter $(m>0) ; \eta$ is the scale parameter $(\eta>0), \gamma$ is the position parameter. If we randomly select $n$ dates of an object failures whose lifetime obeys to the three-parameter Weibull-distribution, the time of failures are $t_{1} \leq t_{2} \leq \leq t_{n}$.

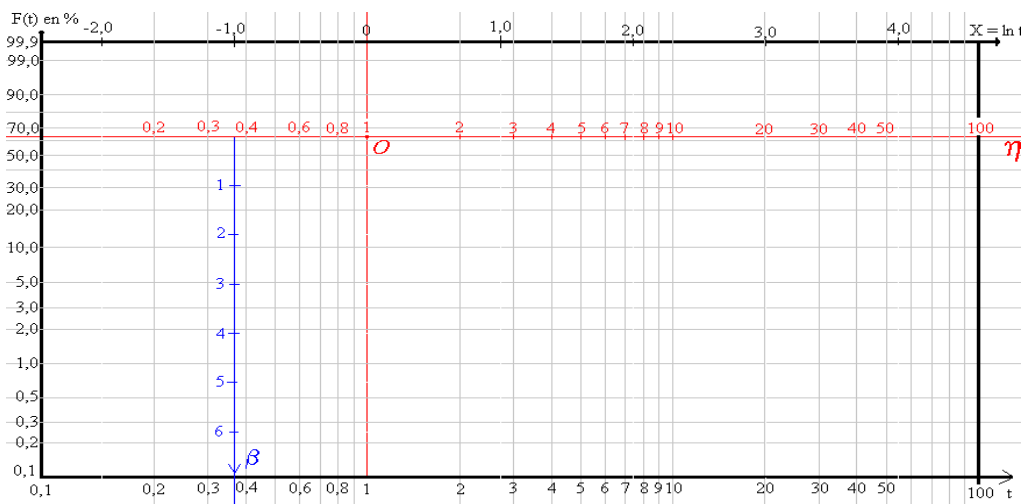

Figure 1: Weibull paper

The associated likelihood function is expressed as a probability density function [6]:

$$
L(m, \gamma, \eta)=\prod_{i=1}^{n} f\left(t_{i}, m, \gamma, \eta\right)=\prod_{i=1}^{n} \frac{d R\left(t_{i}, m, \gamma, \eta\right)}{d t} .
$$

The distributed log-likelihood functions are [7], [8]:

$$
\ln L(t ; m, \eta, \gamma)=n(\ln m-\ln \eta)+(m-1) \sum_{i=1}^{n} \ln \left(\frac{t_{i}-\gamma}{\eta}\right)-\sum_{i=1}^{n}\left(\frac{t_{i}-\gamma}{\eta}\right)^{m} .
$$

Searching separately $\frac{\partial \ln L}{\partial m}, \frac{\partial \ln L}{\partial \gamma}, \frac{\partial \ln L}{\partial \eta}$, and after finishing, the log-likelihood equation is [7][8]:

$$
\begin{gathered}
\frac{1}{m}-\frac{\sum_{i=1}^{n}\left(t_{i}-\gamma\right)^{m} \ln \left(t_{i}-\gamma\right)}{\sum_{i=1}^{n}\left(t_{i}-\gamma\right)^{m}}+\frac{1}{n} \sum_{i=1}^{n} \ln \left(t_{i}-\gamma\right)=0, \\
\frac{m-1}{m} \sum_{i=1}^{n} \frac{1}{t_{i}-\gamma}-\frac{n \sum_{i=1}^{n}\left(t_{i}-\gamma\right)^{m-1}}{\sum_{i=1}^{n}\left(t_{i}-\gamma\right)^{m}}=0, \\
\eta^{m}=\frac{1}{n} \sum_{i=1}^{n}\left(t_{i}-\gamma\right)^{m} .
\end{gathered}
$$


We use $E M V$ in Simulink for the Weibull three-parameter distribution. Using its graphical modeling capabilities, the equations are drawn in the Simulink model window [7], [8]. The estimation of the parameters can be carried out without programming, so handling the Weibull distribution with threeparameters using the $E M V$ solution becomes simple and automatic.

Meaning of the parameters: According to the existing criteria of evaluation of the optimization of maintenance in the industrial world, one distinguishes three major criteria, which are cost, security, availability.

The concept of availability implies three other notions showing the interaction between them. The $D_{o}$ operational availability for an object is related to the ability to be repaired. It reflects the effectiveness of its maintenance and it can be determined as follows: $M T B F /(M T B F+M T T R)$ [10].

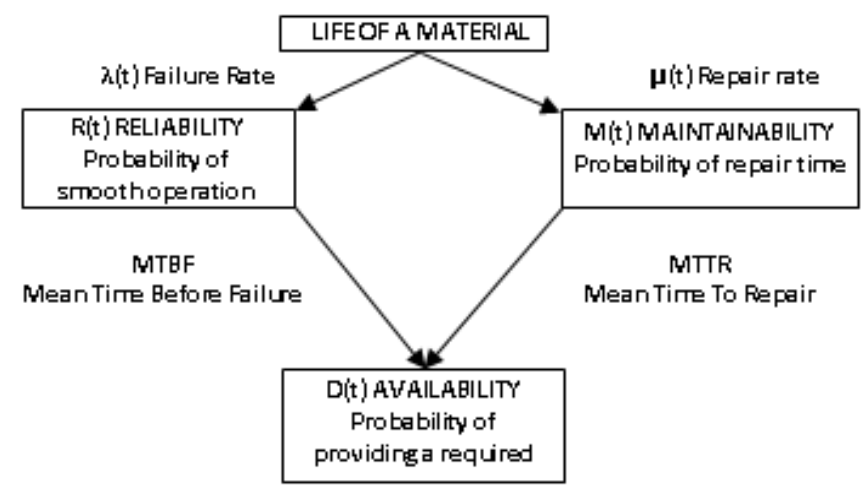

Figure 2: RMA interaction and lifetime of equipment [9]

Parameter analysis: The shape parameter gives the appearance of the distribution of failures $\lambda(t)$. It is dimensionless. Thanks to the estimated value of the form parameter $\beta$, one can model the characteristics of the different phases of the lifetime of an object.

\section{B. Qualitative Study}

According to the history of the machine, we rely on feedback from all operators, which can add value to the analysis. During a limited period the various information obtained are recorded, with a view to updating and ensuring the validity of all the information useful to the study. One of the most used criteria for categorizing failures is the lifetime of the object at the moment of the failure. 


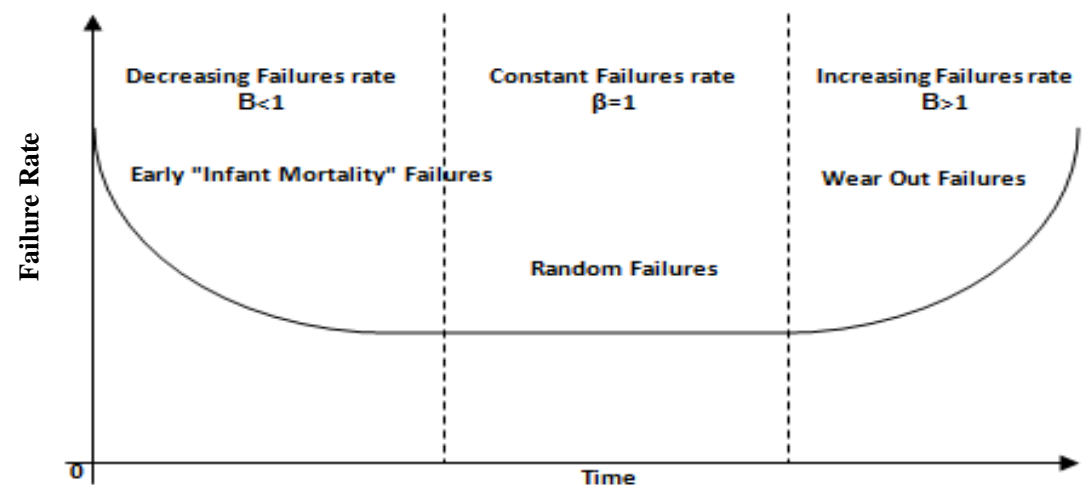

Figure 3: Allure of a failure rate in "bathtub" [11]

Meaning of breakdowns: The operation of the developed algorithm counting the number and the nature of the failures is schematized in a simplified way on Fig. 4. This algorithm is applied for each machine choosing from the list of all failures those in which it is affected by that failure [12].

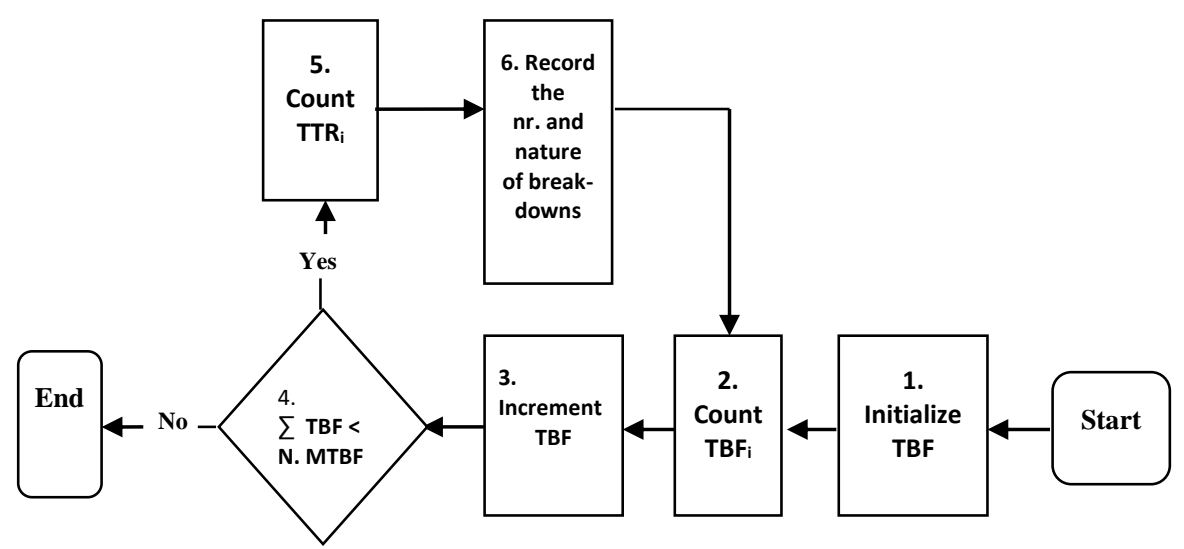

Figure 4: Logical algorithm counting the "Number and Nature" of failures [12]

Failure analysis: The first objective is to insert the fault in the working machine at the exact position where it appeared (Fig. 5).

The classification of the equipment is accordingly to the previously detailed criteria; we can summarize them by the criterion $G$ (gravity), criterion $F$ (occurrence), criterion $D$ (not detected) criterion $C$ (criticality). This analysis will help determine the most critical equipment by using $C=F \cdot G \cdot D$ [14]. 


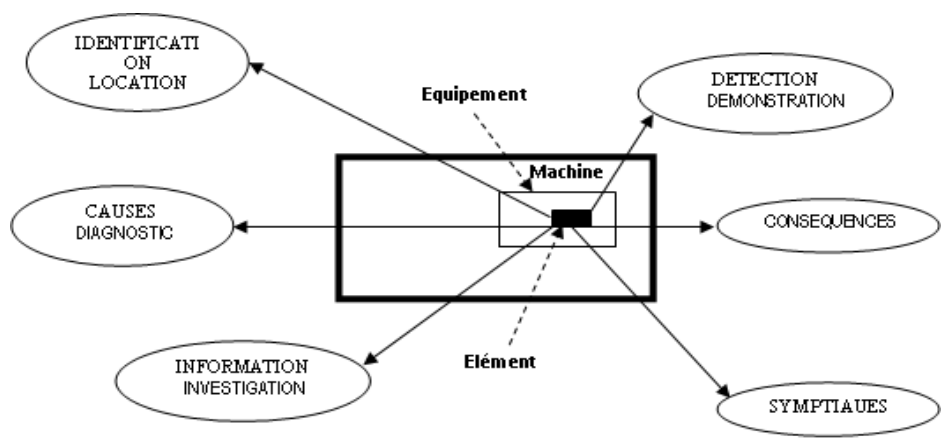

Figure 5: The criteria for inserting a fault in the machine [13]

The second objective is to determine the period $T$ of the systematic intervention. In this policy the Kelly criterion is used in determining the optimal $T$ which corresponds to the optimal period of the systematic intervention. For this it is necessary to know the cost of the reparations $C_{c}$ (which is, by hypothesis, equal to the cost of failure), the cost of the preventive maintenace $C_{p}$ and the parameters of the Weibull-distribution $(\beta$ and $\eta)$. We admit $r=C_{c} / C_{p}$ as the economic criticality ratio of the failure. The range of its validity is $2<r<100$ [15]. On the chart (Fig. O)

$$
x=\frac{T_{0}}{\eta} .
$$

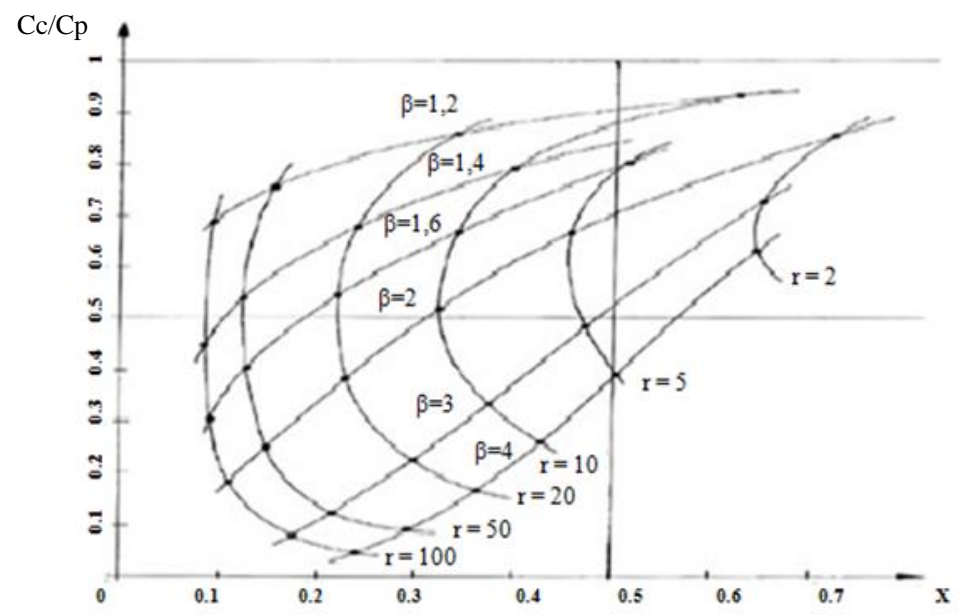

Figure 6: Kelly's abacus 


\section{Approach}

The concept of integrated maintenance relies on the exchange and interaction between these actions, synthetized in three main steps (Fig. 7).

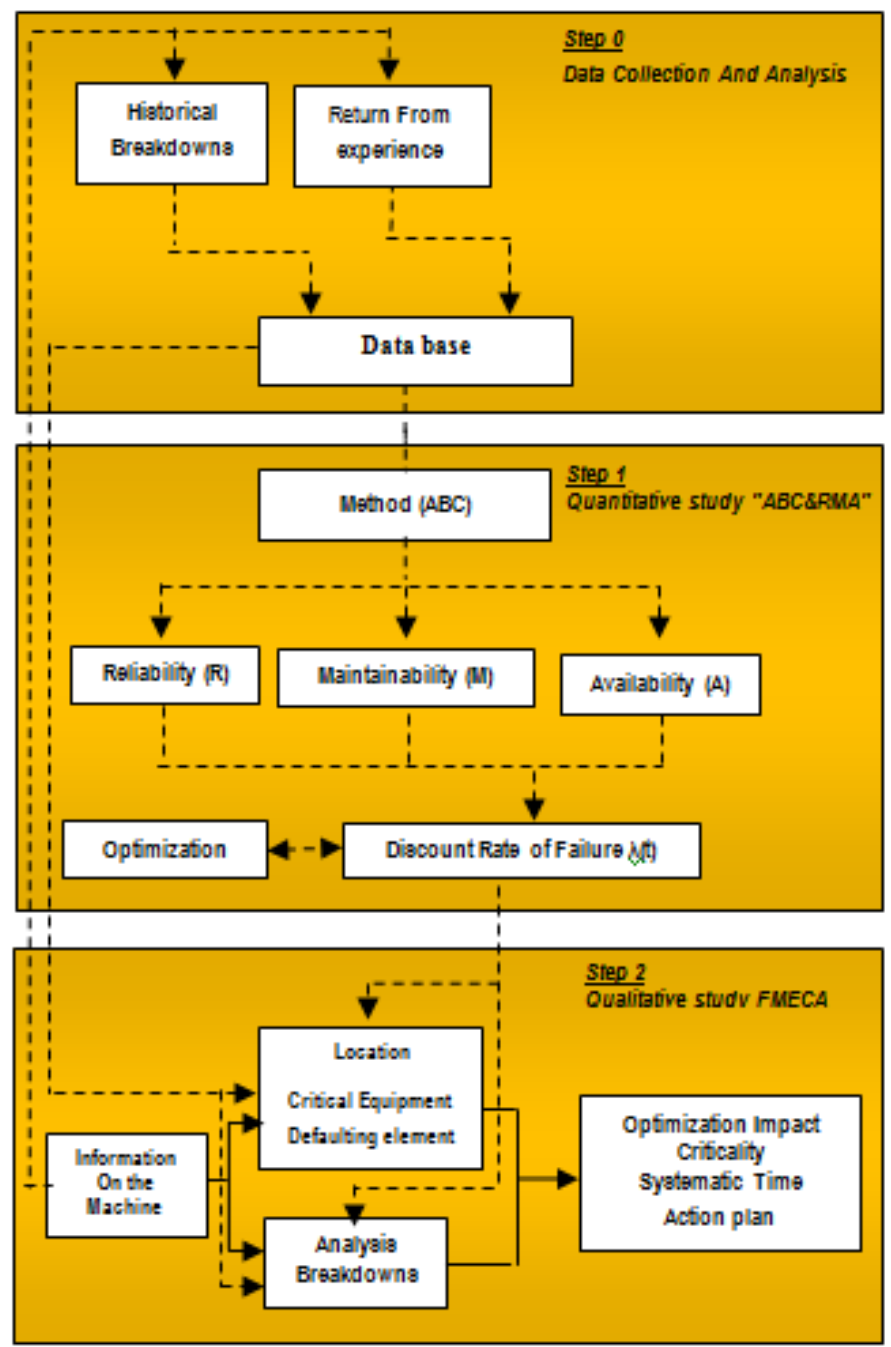

Figure 7: Global approach.

It is particularly important to note that the quantitative study of $R M A$ is generally modeled within the algorithm integrated in the step (1). 


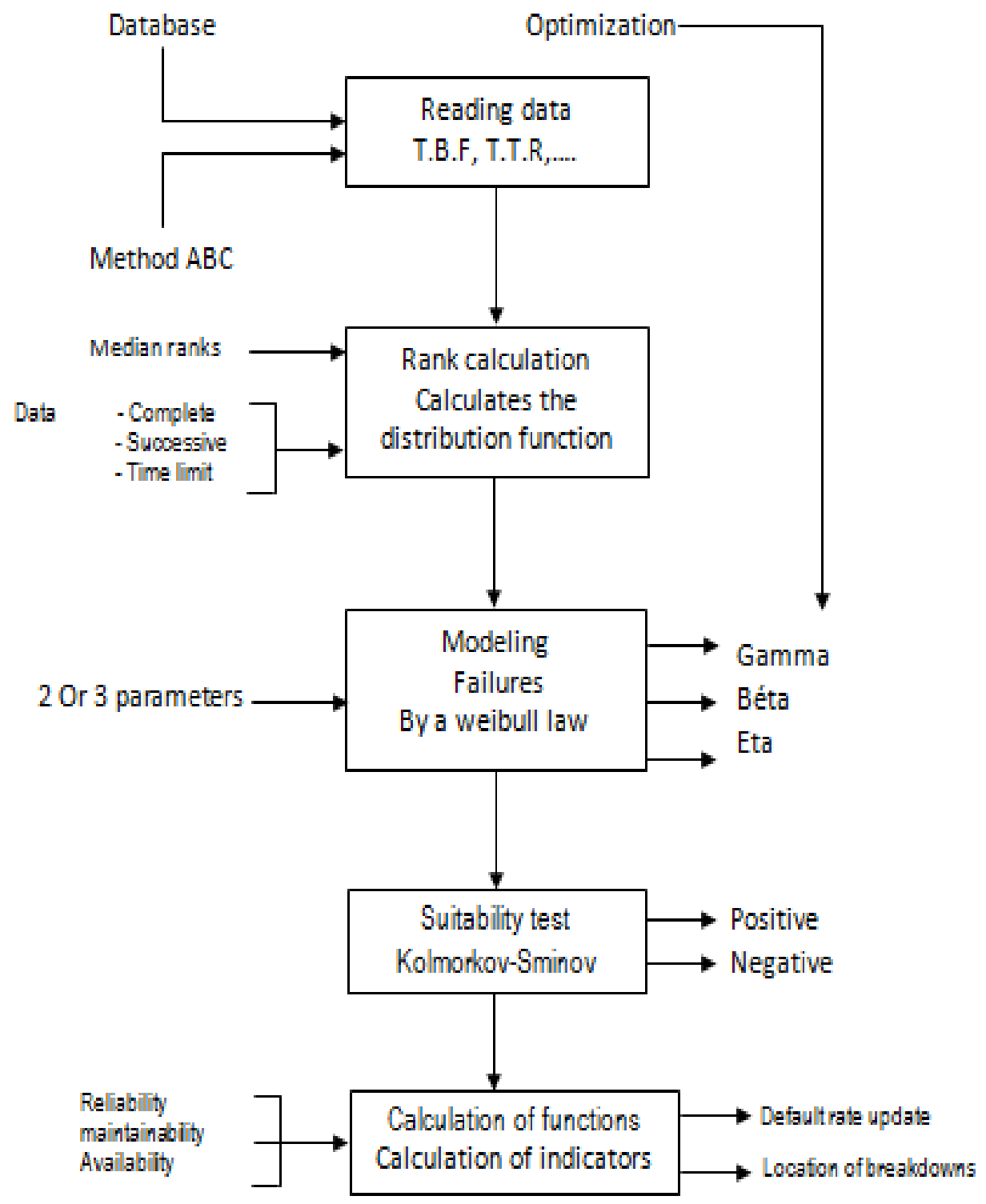

Figure 8: Algorithm of optimization in the quantitative study RMA 


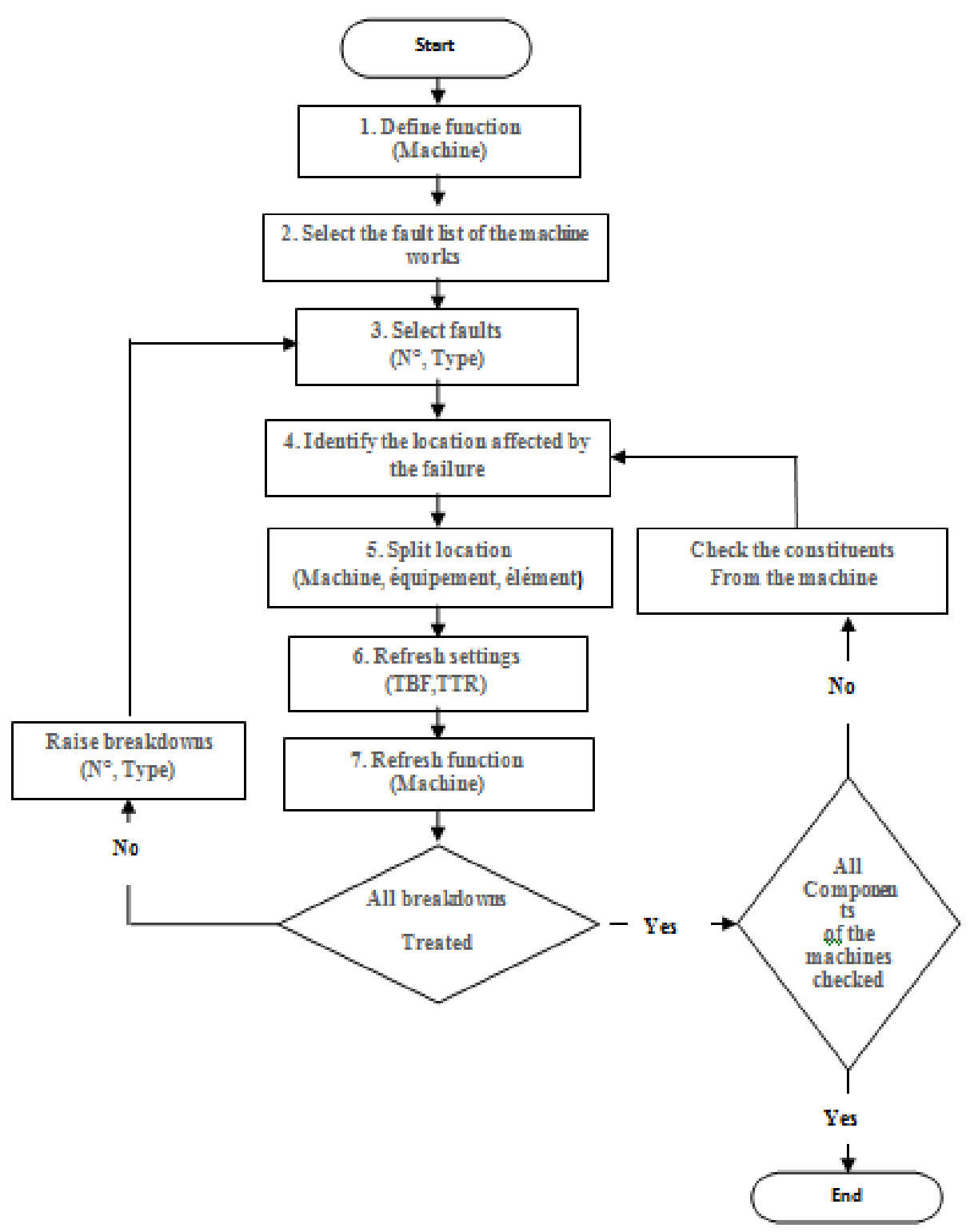

Figure 9: Organizational chart of the optimization procedure strategy

A preliminary optimization phase is necessary. 


\section{Case study: Booster "K101-A" Motor-Compressor of "HBK / Sonatrach ALGERIA"}

The station aims to recover the flared gas in a quantity of $1042000 \mathrm{~m}^{3} / \mathrm{d}$ in order to ship it to the gas treatment unit.

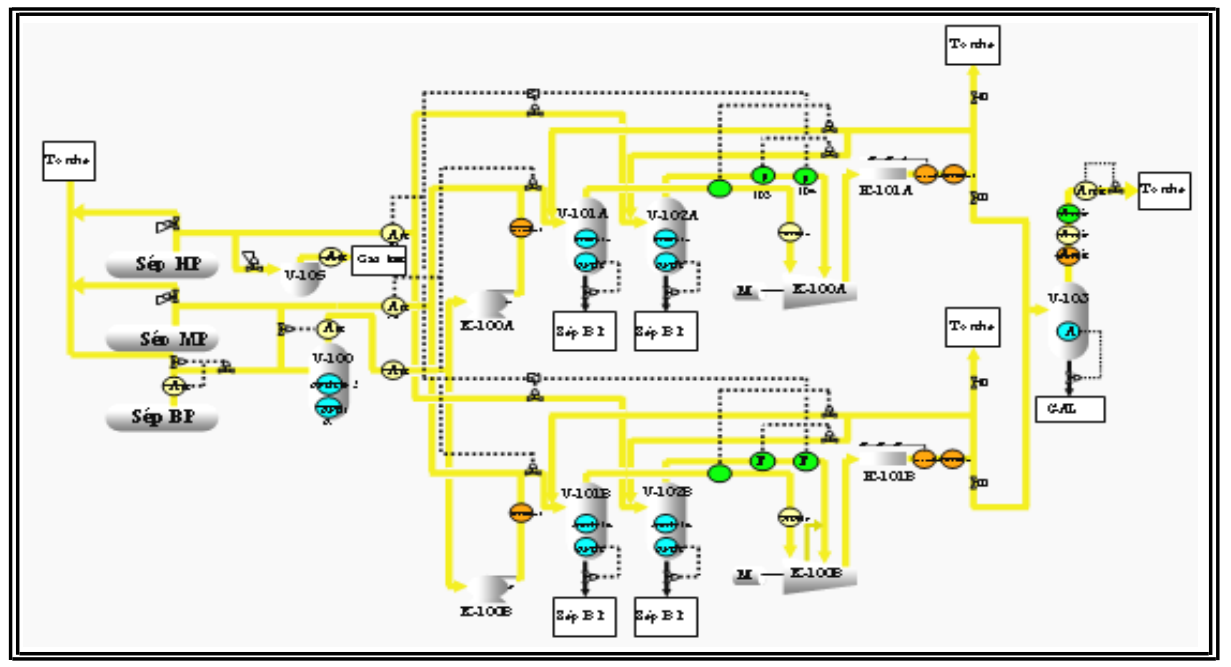

Figure 10: Process diagram of HBK Boosting Station

It usually consists of suction flasks, two motor compressors, a cooling system and a starting flask to recover condensates. $H B K$ booster motors $(A$ and $B)$ are of the centrifugal type and driven by electric motors [17].

\section{A. Quantitative and qualitative study}

This study is based on the number of breakdowns to each equipment during the period between 1994 and 2004. The $A B C$ curve is used to select the elements to be considered in our study. It is used to rank the equipment in an order of priority. 
Table 3: Overall ranking of elements [18]

\begin{tabular}{|c|c|c|c|c|}
\hline Designations & $\mathrm{N}^{\circ}$ order & $\mathrm{N}^{\text {br }}$ failures & plurality & Failure (\%) \\
\hline Lubricant Circuit /Compressor & 1 & 04 & 04 & 18.18 \\
\hline Alignment Tree /Compressor & 2 & 02 & 06 & 27.27 \\
\hline Pallier / Motor & 3 & 03 & 09 & 40.90 \\
\hline Water Sealing Circuit /Compressor & 4 & 02 & 11 & 50 \\
\hline Alignment Tree / Motor & 5 & 01 & 12 & 54.54 \\
\hline Transformer of Start / Motor & 6 & 01 & 13 & 59.09 \\
\hline Pallier / Multiplier & 7 & 02 & 15 & 68.18 \\
\hline Regulatory chain Vibration / Compressor & 8 & 02 & 17 & 7.27 \\
\hline Power Panel / Motor & 9 & 02 & 19 & 86.36 \\
\hline Lubricant Pump /Multiplier & 10 & 01 & 20 & 90.90 \\
\hline Antipump loop /Compressor & 11 & 01 & 21 & 95.45 \\
\hline Transmitter Temperature / Multiplier & 12 & 01 & 22 & 100 \\
\hline
\end{tabular}

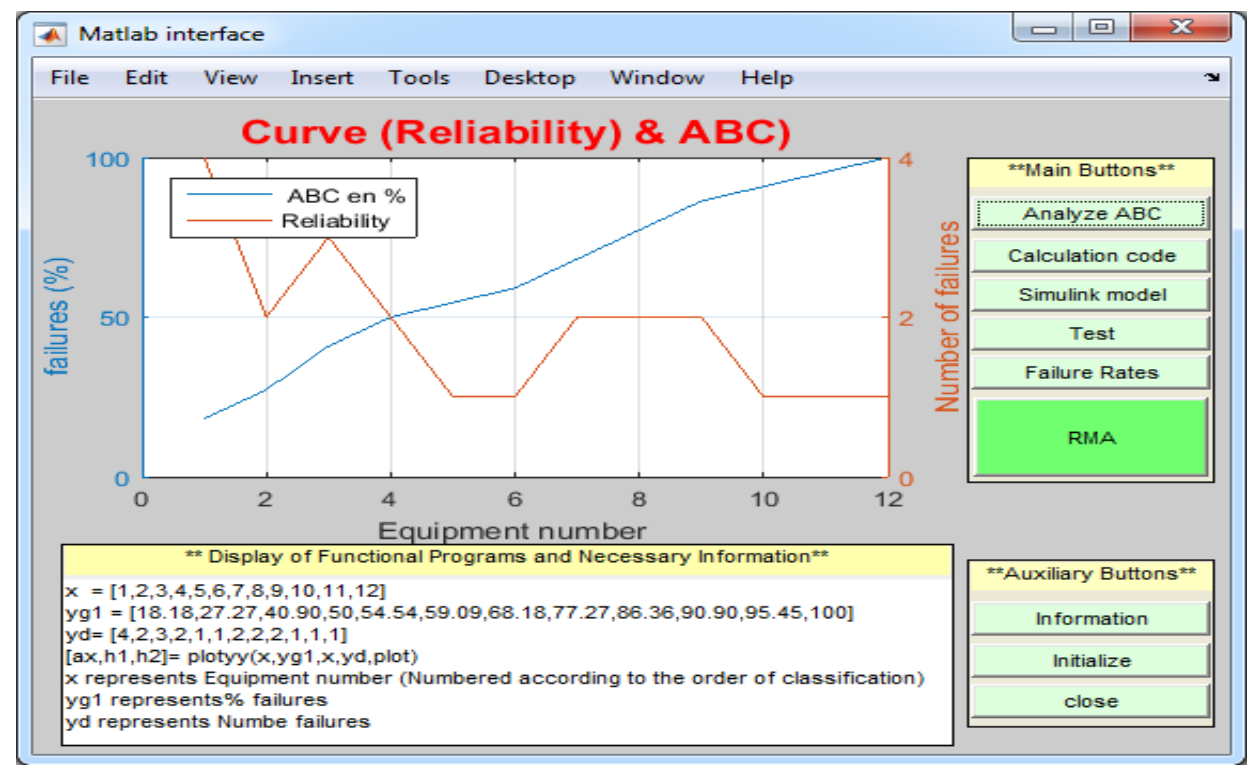

Figure 11: Curves (Reliability \& ABC) 
Zone $A: 25 \%$ of equipment, representing 50 to $70 \%$ of the numbers of failure. They are therefore to be studied in priority the compressor.

It is concluded from the analysis made above that the equipment requiring support for its maintenance is the compressor; it is the most critical equipment.

Table 4: Preparation of the application data

\begin{tabular}{|c|c|c|c|c|c|}
\hline$N^{\circ}$ & $T T R(\mathrm{~h}: \mathrm{m})$ & $T B F(\mathrm{~h}: \mathrm{m})$ & $F_{\text {estimated }}$ & $T B F \times(1 / 150)$ & $F(\%)$ \\
\hline 1 & $14: 30$ & $22: 40$ & 0.0614 & 0.149 & 6.14 \\
\hline 2 & 16 & 1681 & 0.1491 & 11.20 & 14.91 \\
\hline 3 & $17: 30$ & $1971: 30$ & 0.2368 & 13.14 & 23.68 \\
\hline 4 & 18 & 2510 & 0.3245 & 16.73 & 32.45 \\
\hline 5 & $18: 30$ & 2522 & 0.4122 & 16.81 & 41.22 \\
\hline 6 & 23 & $4030: 10$ & 0.5 & 26.86 & 50 \\
\hline 7 & 24 & 4213 & 0.5877 & 28.08 & 58.77 \\
\hline 8 & 48 & 5110 & 0.6754 & 34.06 & 67.54 \\
\hline 9 & 54 & $5685: 10$ & 0.7681 & 37.90 & 76.81 \\
\hline 10 & 56 & 5712 & 0.8508 & 38.08 & 85.08 \\
\hline 11 & $56: 30$ & 6984 & 0.9385 & 46.56 & 93.85 \\
\hline
\end{tabular}

Two parameters: The graphical determination of the parameters through the Weibull paper which has been validated by a calculation code. 


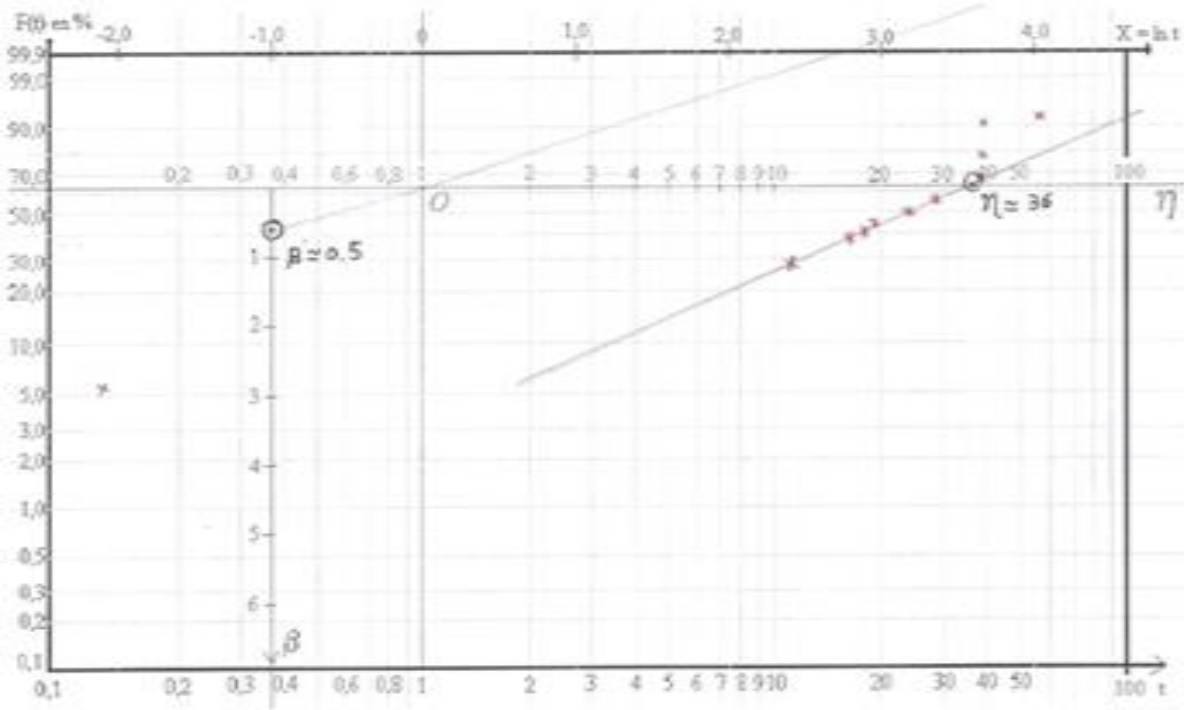

Figure 12: Weibull paper

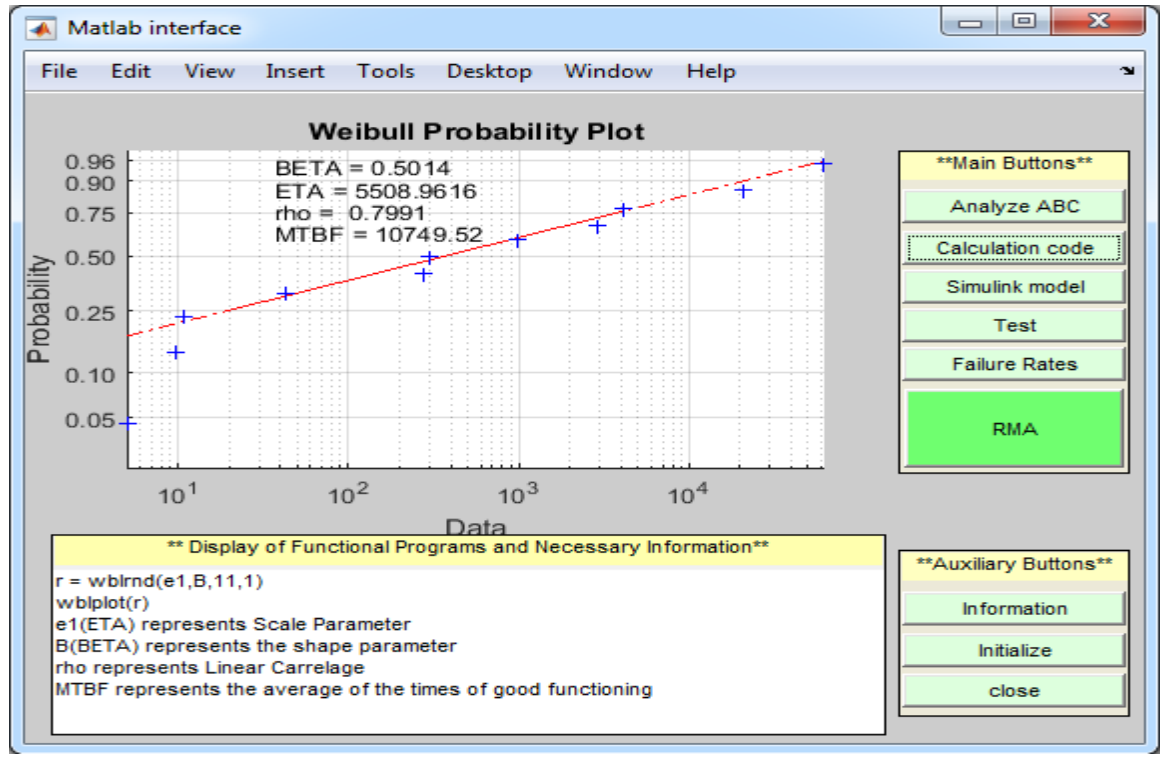

Figure 13: Weibull probability plot (calculation code)

It makes possible to find the critical hints of failure of the analyzed equipment:

$\beta=0.50 ; \gamma=0 ; \eta=5509$. 
Three parameters: the $E M V$ will be implemented in a Simulink-model.

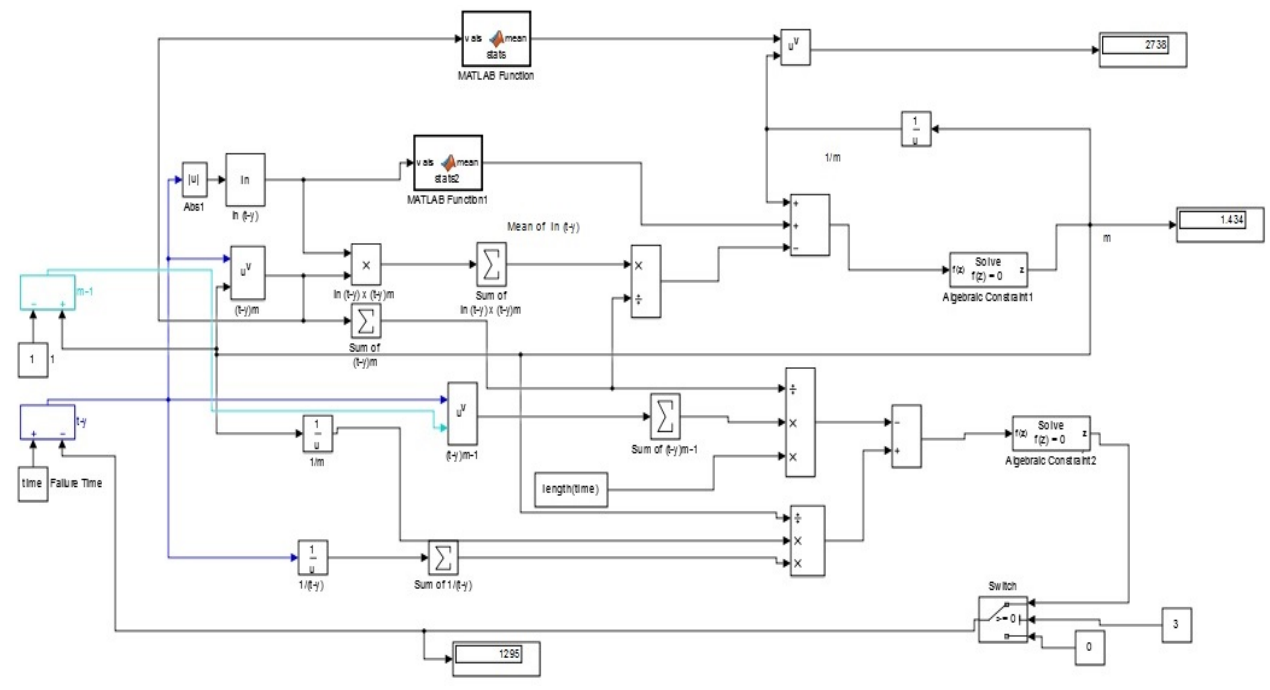

Figure 14: EMV Simulink model, $\beta=1.434 ; \gamma=1295 ; \eta=2738$

Analysis and meaning: we have to test the Weibull model.

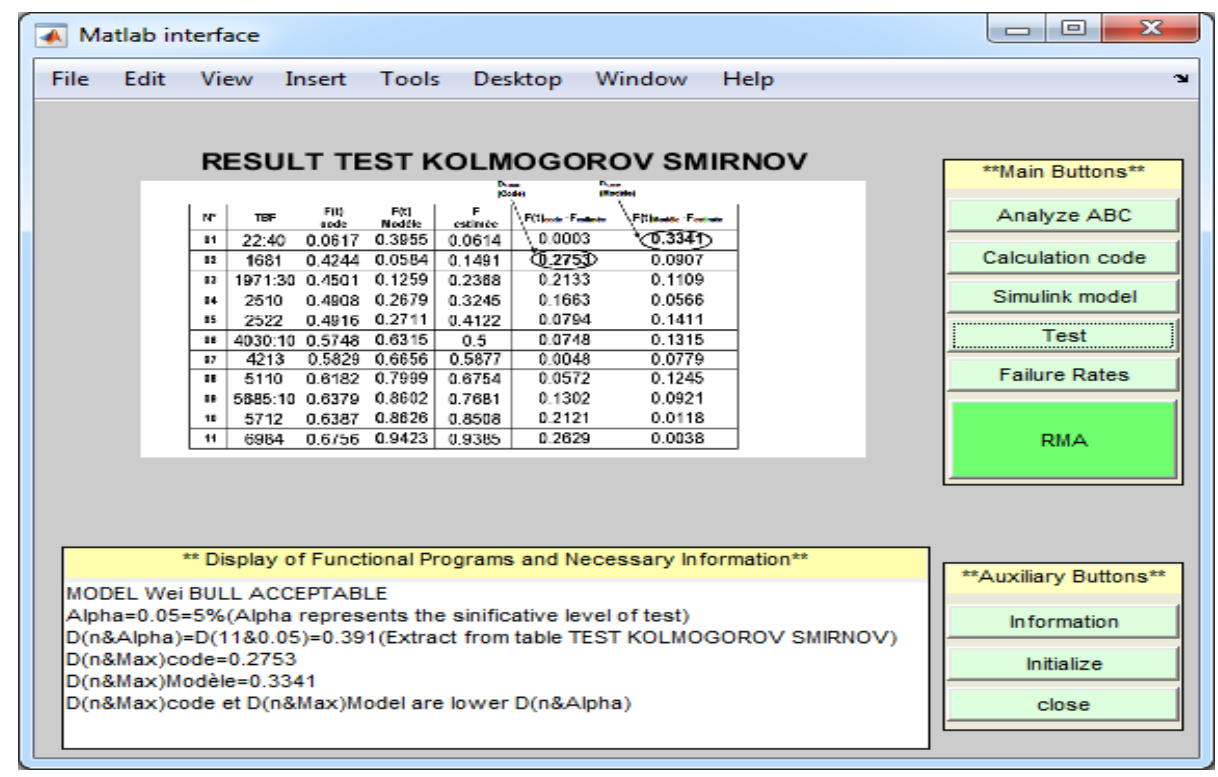

Figure 15: Kolmogorov-Smirnov test 
Updating the evolution of the failure rate gives two different age scales:

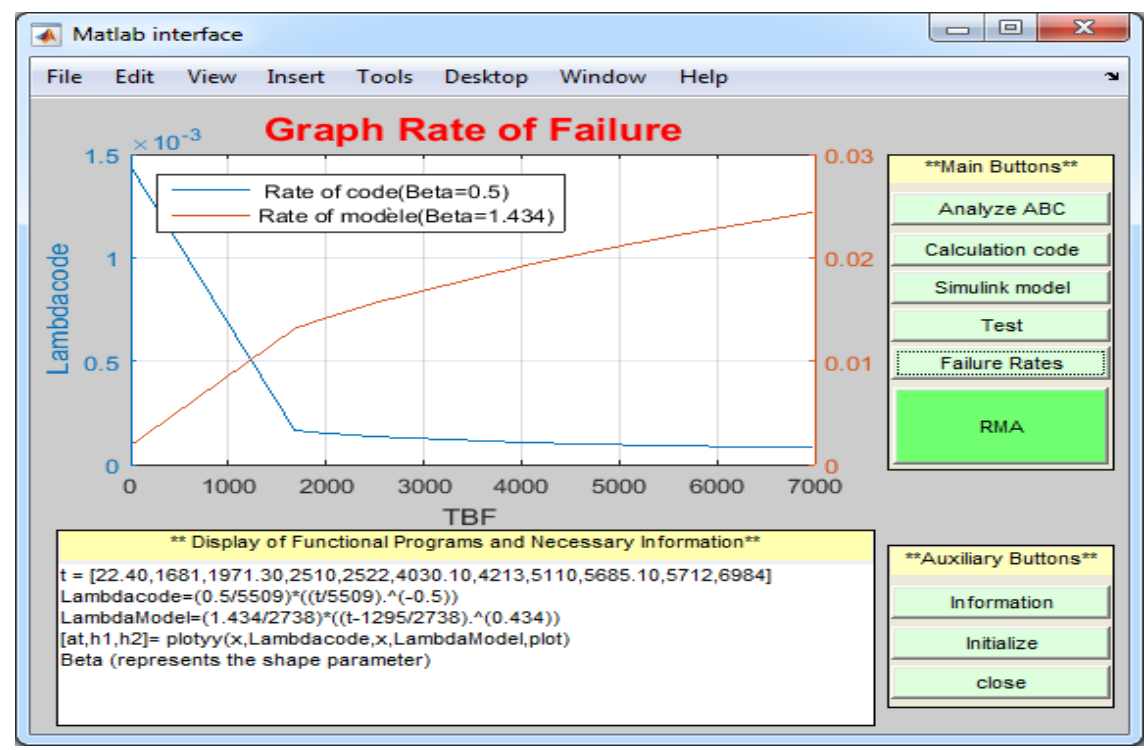

Figure 16: Allures of the rate of failure

The period of youth $(\beta=0.50)$ and the period of wear "old age" $(\beta=1.434)$.

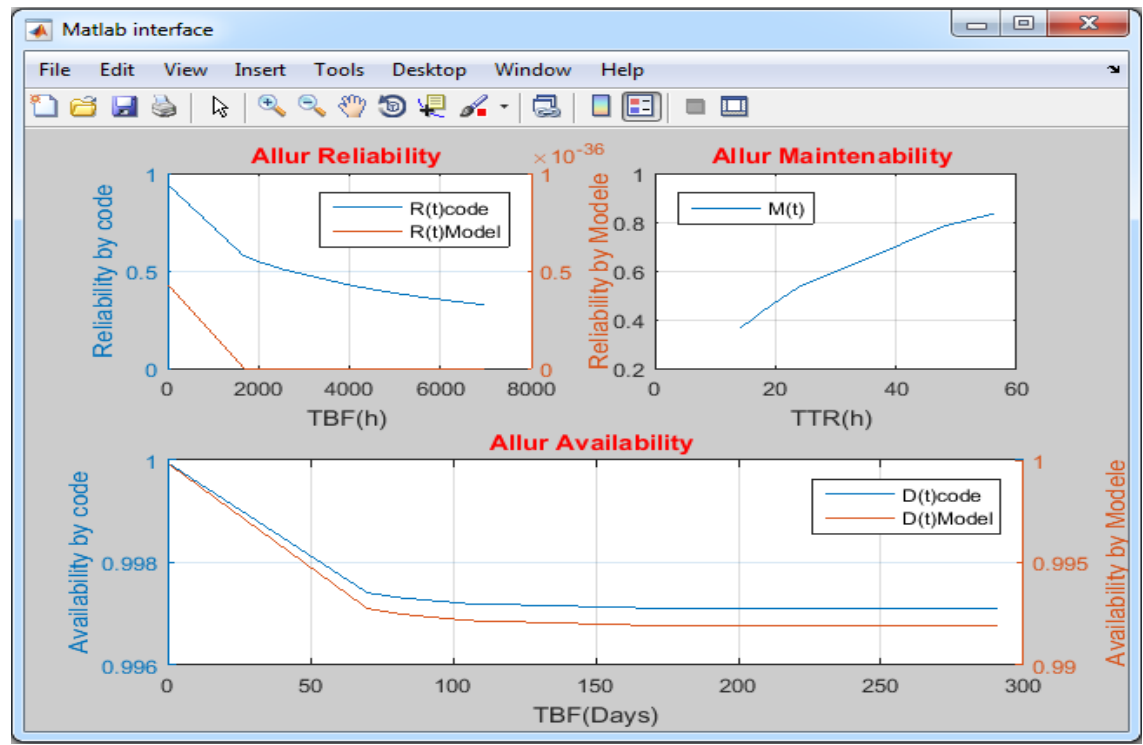

Figure 17: Allures RMA 
The results obtained after the calculation are according to the equations:

$$
M(t)=1-\mathrm{e}^{\mu \cdot t}, R(t)=\mathrm{e}^{-\left[\frac{t-\gamma}{\eta}\right]^{\beta}}, D(t)=\frac{\mu}{\lambda+\mu}+\frac{\lambda}{\lambda+\mu} \cdot \mathrm{e}^{-(\mu+\lambda) \cdot t},
$$

which allows to draw the above allure of $R M A$ for the two procedures: $\beta=0.50$, $\beta=1.434$.

Reliability, between the two procedures there is almost a difference of 0.5 (50\%) from the beginning to the end of the phase which directly affects the cost of the maintenance (repairs).

Maintainability, shows that the two procedures ensure a direct proportionality between $T T R$ and $M(t)$ which directly affects the security maintenance.

Availability, in the beginning $T B F 0$ to 70 days, the two procedures shows a rapid regression but from 70 to 290 days there is a constant availability with a difference of approximately $0.05(5 \%): D_{o}($ code $)=0.96, D_{o}($ model $)=0.91$. The criteria of optimization gives:

Table 5: Optimization criteria

\begin{tabular}{|c|c|c|c|}
\hline Procedures & Cost & security & Availability \\
\hline Calcul Code & less & critical & more \\
\hline Simulink Model & more & critical & less \\
\hline
\end{tabular}

According to the criteria of criticality in this phase of aging $\beta=1.434$.

Table 6: Determination of criticality

\begin{tabular}{|c|c|c|c|c|}
\hline failures & N Nre/TBF $^{\text {Nature }}$ & Integration & criticality \\
\hline Labyrinth seals & $04 / 11275$ & Break/fissure & Lubricant circuit & 8 \\
\hline Gasket of sealing & $02 / 4203$ & Wear & Water circuit & 20 \\
\hline Mechanical Garnish & $02 / 11197$ & Break/fissure & Chain of vibration & 12 \\
\hline Bearing & $02 / 7656$ & Deformation & Alignment shaft & 18 \\
\hline
\end{tabular}

The model of Kelly to determine the optimum time of intervention based on the direct and indirect cost of maintenance. 
Table 7: Corrective and preventive maintenance costs "gasket sealing"

\begin{tabular}{|c|c|c|}
\hline Cost & $C_{c}(\mathrm{DA})$ & $C_{p}(\mathrm{DA})$ \\
\hline Corrective & 67960 & $/$ \\
\hline Preventive & $/$ & 211820 \\
\hline
\end{tabular}

By using the abacus of Kelly, for $r=3$ and $\beta=1.434$ we extract the value $x=0.6$ which requires the optimal time of systematic intervention equal to $T_{o}=1643$. Action plan, the obtained strategy of maintenance is required and adopted by FMECA.

\begin{tabular}{|c|c|c|c|c|c|c|c|c|c|c|}
\hline \multicolumn{2}{|c|}{$\begin{array}{l}\text { Machine: motorcyde compressor } \\
\text { Equipment: Compressor }\end{array}$} & \multicolumn{9}{|l|}{ Dated: } \\
\hline \multirow{2}{*}{ The element } & \multirow{2}{*}{ function } & \multirow{2}{*}{ Failure mode } & \multirow{2}{*}{ causes } & \multirow{2}{*}{ effects } & \multirow{2}{*}{ detection } & \multicolumn{4}{|c|}{ criticality } & \multirow{2}{*}{$\begin{array}{l}\text { Action to engage } \\
\text { (Maintenance type) }\end{array}$} \\
\hline & & & & & & $\mathrm{F}$ & G & D & $\mathrm{C}$ & \\
\hline gasket of sealing & $\begin{array}{c}\text { Ensure of } \\
\text { sealing }\end{array}$ & Usury & Tired & \begin{tabular}{|c|} 
overheati \\
ng
\end{tabular} & Oil leak & 5 & 4 & 1 & 20 & $\begin{array}{l}\text { Verification and Change } \\
\text { (Corrective \& Preventive) }\end{array}$ \\
\hline bearing & $\begin{array}{c}\text { Keep the } \\
\text { rotor } \\
\text { position }\end{array}$ & Deformation & Tired & $\begin{array}{c}\text { Bad } \\
\text { rotation } \\
\text { Rotor } \\
\end{array}$ & Visual & 3 & 3 & 2 & 18 & $\begin{array}{l}\text { Change of bearing } \\
\text { (Corrective) }\end{array}$ \\
\hline Mechanical Garnish & $\begin{array}{c}\text { Ensure of } \\
\text { sealing }\end{array}$ & $\begin{array}{l}\text { - Break } \\
\text { - fissure } \\
\end{array}$ & Tired & \begin{tabular}{|c|} 
overheati \\
$\mathrm{ng}$
\end{tabular} & Oil leak & 4 & 3 & 1 & 12 & $\begin{array}{l}\text { Change } \\
\text { (corrective) }\end{array}$ \\
\hline Labyrinth seals & $\begin{array}{c}\text { Reduce gas } \\
\text { leaks }\end{array}$ & $\begin{array}{l}\text { - Break } \\
\text { - fissure }\end{array}$ & $\begin{array}{l}\text { - Corrosion } \\
\text { - overloading }\end{array}$ & $\begin{array}{l}\text { Increased } \\
\text { gas leak }\end{array}$ & $\begin{array}{l}\text { Low flow } \\
\text { and gas } \\
\text { pressurese }\end{array}$ & 4 & 2 & 1 & 8 & $\begin{array}{l}\text { Treatment andreplacement of seals } \\
\text { (Corrective \& Preventive) }\end{array}$ \\
\hline
\end{tabular}

\section{Conclusion}

In this article it is shown the impact of the optimization of the integrated maintenance on the strategic machine lifetime. The approach is based on two qualitative analysis $\mathrm{ABC}$, RMA, and the quantitative FMECA. In this approach, the two procedures are presented as code calculation and Simulink model by the use of Weibull-distribution law. The first one, namely the graphical method via Weibull-distribution, has two parameters $(\beta=0.50, \eta=5509)$ and the second is based on the maximum likelihood method (EMV) with a Weibull-distribution with three parameters $(\beta=1.434, \gamma=1295, \eta=2738)$. MATLAB software is used in the both procedures, both in programming and Simulink modelling. The implementation of such approach demonstrates its contribution to maintaining machine lifetime. Indeed, it permitts a better estimation of the operational availability of the studied machine, resulting $D_{0}$ (code) $=0.96$, and $D_{0}($ model $)=0.91$. The criticality of 20 identifies the critical element on which a particular attention is to be applied by the optimal time for systematic 
intervention of 1643 hours. Briefly, the approach has constituted an actual way to the optimization of the actions of the maintenance.

\section{References}

[1] Mebarkia, D., "Search for an optimal solution for the operation and maintenance of Algerian pipelines taking into account the reliability of the equipment of the different lines", Magister thesis, Reliability Laboratory of Equipment and Materials, Faculty of Hydrocarbons and Chemistry, University of Boumerdes, Joins 2013.

[2] Marc, T., "Predictive maintenance reliability and vibration of machines", University Presses of Québec, 2012.

[3] Meslameni, W., "Optimization of maintenance times of a gas turbine Optimisation des temps de maintenance d'une turbine à gaz", International Journal of Applied Research and Technology, vol 1, 2018.

[4] Homeomath, Papier de Weibull, "http://homeomath2.imingo.net/loiweibull2.htm".

[5] Yang, M., Nie, H., "Advanced Algorithm for Maximum Likehood Estimation of Three Parameter Weibull Distribution", Journal of Nanjing University of Aeronautics\& Astronautics, 39(1), pp. 22-25, 2007.

[6] Mfetoum, I. M., Essiane, S. N., "Estimation of Weibull model parameters: application to the modeling of the reliability of the CAMRAIL railway ballast mechanical tapping machine”, Journal of Science, Technology and Development, Special Edition, pp. 117-121, July 2016.

[7] Shi, J. Z., Shao, R., Chen, X., "Weibull distribution based on Matlab / Simulink Maximum likelihood estimation", Journal of Henan Science, Vol.29, 1004-3918, 2011.

[8] Shi, J. Z., et al., "Random Censored Data MLE of Weibull Distribution Based on Simulink", Advanced Materials Research, Vols. 542-543, pp. 1463-1466, 2012.

[9] Celeux, G., Corset, F., Lannoy, A., Ricard, B., "Designing a bayesian network for preventive maintenance from expert opinions in a rapid and reliable way", Reliability Engineering and System Safety, vol. 91(7), pp. 849-856, 2006.

[10] Bensaci, M. A., "Management of a maintenance integrated into the centrifugal compressor motorcycle k 101-A", Magister thesis, Electromechanical Systems Research Laboratory, Department of Electromechanics, Annaba University, 2006.

[11] Harish, K. N. S., Choudhary, R. P., Murthy, Ch. S. N., "Failure Rate Analysis of Shovel and Dumper in Opencast Limestone Mine using RWB and ANN", International Journal of Innovative Technology and Exploring Engineering (IJITEE), vol. 8, Issue 5, March, 2019.

[12] Samir, H., "Model of performance evaluation of a production line of a sequence of $n$ distinct products on $\mathrm{m}$ machines with $(\mathrm{ml})$ buffer stocks", MSc Thesis, Department of Mechanical Engineering Faculty of Science and Engineering, University Laval Quebec, 2012.

[13] Bouanaka, M.L., "Contribution to the improvement of the operational performances of the industrial machines", Memory presented for the diploma of magister in mechanical engineering, Department of Mechanical Engineering, Faculty of Sciences of the Engineer, University of Constantine, 2008/2009.

[14] Donier, L., Sansberro, D., Barthod, V., Clerget, E., Tissot, D., "AMDEC risk analysis of the preparation of doses to be administered by a dry oral forms automation", International Journal of Science Direct, Vol. 52, Issue 1, pp. e42-e43, March 2017.

[15] Lyonnet, P., "The mathematical maintenance and methods", $4^{\text {th }}$ edition, LAVOISIER, October 2000. 
[16] Fadhil, A., "A Comparison Between the Bayesian and the Classical Estimators of Weibull Distribution", Journal of Kufa for Mathematics and Computer, Vol.1, No.8, Dec 2013.

[17] Habbel, L., Boucetta, O., "Study and Maintenance of a Centrifugal Compressor", Final Thesis for Engineering Diploma, Faculty of Hydrocarbons and Chemistry, Department of Transport and Hydrocarbon Equipment, University Mohamed Bougara Boumerdes, 2006.

[18] Bensaci, M.A., "Historical Tables Breakdowns of a K-101A Motocompressor", Internship Report, Sonatrach in Division Production Branch Regional HUD Berkaoui Maintenance Division, 2006. 